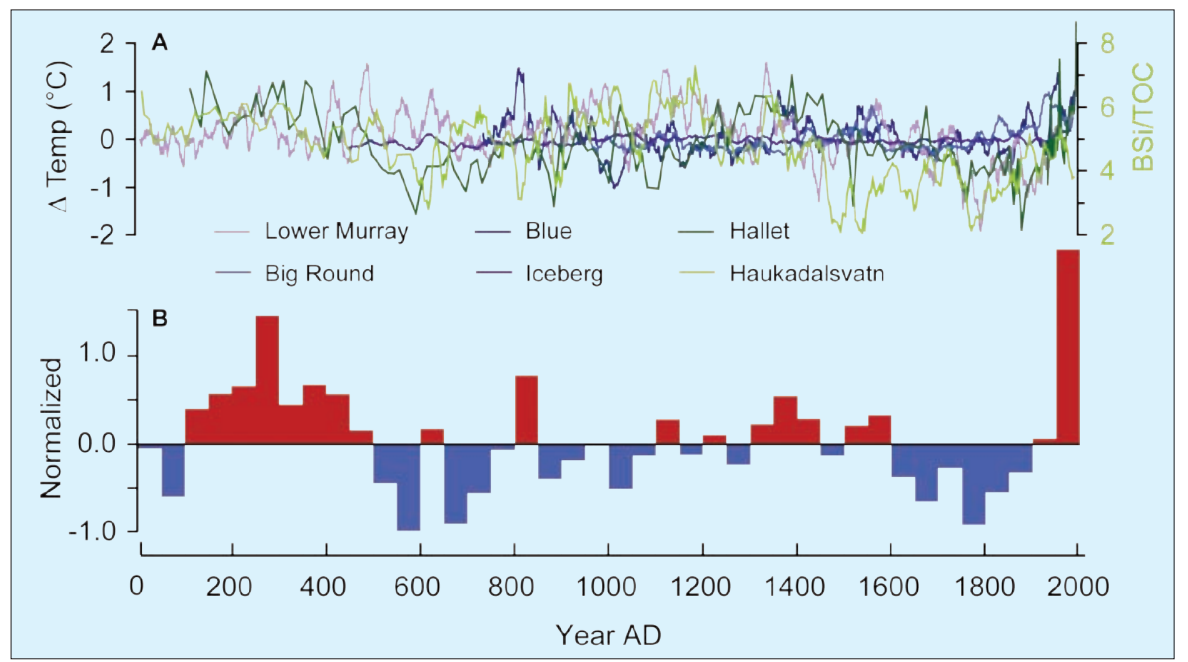

Figure 2: Summary of the 6 new proxy climate records from Arctic lakes with sub-decadal to annual resolution. $\boldsymbol{A}$ ) 5 records were calibrated using instrumental climate records to infer past summer temperature and are plotted as anomalies relative to the average of the last millennium ( $\triangle T$ Temp). 1 record (Haukadalsvatn) was not calibrated and is plotted according to the raw ratio of biogenic-silica to total-organic content (BSi/TOC); $\boldsymbol{B}$ ) The records were stacked by binning the data into 50-year intervals, normalizing each to a mean of zero and a variance of 10 , then averaging the values for each bin. The records include Lower Murray Lake (Cook et al.), Big Round Lake (Thomas and Briner), Blue Lake (Bird et al.), Iceberg Lake (Loso), Hallet Lake (McKay and Kaufman), and Haukadalsvatn (Geirsdóttir et al.).

lake in southern Alaska to infer changes in the trajectory of storm tracks in a region dominated by the influence of the Aleutian low-pressure system.

\section{High-resolution records}

Of the new proxy records, six are resolved at sub-decadal to annual scale, including four based on varve thicknesses and two on biogenic-silica content (Fig. 2). They were calibrated using instrumental climate records to develop regression models to infer numerical values of past summer temperature downcore. The temperature variation for these records averages $\pm 0.73^{\circ} \mathrm{C}(1 \sigma)$. Stacking the records by binning the data into 50 -year intervals, normalizing each to a mean of zero and a variance of $1 \sigma$, then averaging the values for each bin reveals a coherent structure to the time series. Most striking is the most recent half-century, which exhibits the single highest average normalized temperature values and a shift to higher temperatures that is twice as large as any other consecutive interval during the last 2 kyr. leoclimate archives. These will be used to investigate the spatial and temporal variability of climate change in the Arctic, and will be integrated into experiments using general circulation models. These data-model comparisons are aimed at distinguishing patterns of forced climate change from internal variability in the Arctic climate system. The effort will be part of the PAGES Arctic $2 k$ initiative and will be facilitated by data management provided through the World Data Center for Paleoclimatology (www.ncdc.noaa.gov/paleo/) and the PAGES Arctic2k Metadatabase (www.pages.unibe.ch/science/arctic2k/). More information about this project, including an overview of the climate-modeling component, is available at: www.arcus. org/synthesis $2 \mathrm{k} /$

\section{Acknowledgements}

I thank the authors of the 14 papers now in press in the Journal of Paleolimnology, and the 41 peer reviewers for their generous input. I thank $M$. Brenner and T. Whitmore for editorial support, N. McKay for data analysis, and the WDC for Paleoclimatology for data archival. Research and project coordination were funded primarily by the US-NSF Arctic System Science Program. (800-1600 AD) does not exhibit a coherent pattern of temperature fluctuations, nor evidence for a constantly warm Medieval period. Instead, 100-500 AD is the most protracted warm period. This result is based on only three proxy records that extend the full duration of the last $2 \mathrm{kyr}$ but is consistent with the first-order trend of overall cooling that is exhibited by the lower-resolution records reported by other papers in the special issue. It also suggests that as new high-resolution proxy records are generated, a warm interval more pronounced than during Medieval times will emerge as a prominent feature of Arctic climate during the first millennium AD.

\section{Future plans}

In the future, the new lacustrine proxy records will be integrated into a larger network of sites that includes other pa-

\section{References}

Bird, B.W., Abbott, M.B., Finney, B.P. and Kutchko, B., in press: A 2000 year varve-based climate record from the central Brooks Range, Alaska, Journal of Paleolimnology, 41 (1): Jan. 2009.

Cook, T., Bradley, R.S., Stoner, J.S. and Francus, P., in press: Five thousand years of sediment transfer in a High Arctic watershed recorded in annually laminated sediments from Lower Murray Lake, Ellesmere Island, Nunavut, Canada, Journal of Paleolimnology, 41(1): Jan. 2009.

Geirsdóttir, A., Miller, G.H., Thordarson, T. and Ólafsdóttir, K.B., in press: A 2000 year record of climate variations reconstructed from Haukadalsvatn, west Iceland, Journal of Paleolimnology, 41(1): Jan. 2009. Period and Little Ice Age inferred from varved proglacial lake sediments in southern Alaska, Journal of Paleolimnology, 41(1): Jan. 2009.

McKay, N.P. and Kaufman, D.S., in press: Holocene climate and glacier variability at Hallet and Greyling Lakes, Chugach Range, southcentral Alaska, Journal of Paleolimnology, 41(1): Jan. 2009.

Thomas, E.K. and Briner, J.P., in press: Climate of the past millennium inferred from varved proglacial lake sediments, northeast Baffin Island, Arctic Canada, Journal of Paleolimnology, 41(1): Jan. 2009.

For full references please consult:

www.pages-igbp.org/products/newsletters/ref2009_1.html
Loso, M.G., in press: Summer temperatures during the Medieval Warm

\title{
Holocene paleoclimate of the Canadian Arctic Islands: The ACVAST project
}

Konrad Gajewski ${ }^{1}$, M. Peros ${ }^{1}$, S. Finkelstein ${ }^{2}$ and M. Fortin ${ }^{1}$

'Department of Geography and Ottawa-Carleton Institute of Biology, University of Ottawa, Canada; gajewski@uottawa.ca; Department of Geography, University of Toronto, Canada

Multi-proxy studies of a series of lakes across the Canadian Arctic Islands are providing the first continuous and quantitative estimates of Holocene climate variability for the region. These reconstructions highlight the impact of climate variations on biological production and biodiversity in Arctic ecosystems.

Arctic ice cores provide critical records of Holocene climate variability. However, to map the spatial patterns of past climates and explain local ecological responses to climate variability, an extensive array of sites is needed. Continuous records from lake sediments provide a major source of information toward this goal. 
The largest extent of tundra in the world is in the Canadian Arctic Archipelago, yet the postglacial environmental history of this region is little known. As opposed to Greenland, where numerous studies of both ice cores and lake sediments have been undertaken, few series from the Canadian Arctic have been published. In addition to difficult access and high costs, a deterrent to funding of Arctic lake sediment studies has been the perception, in North America at least, that pollen analysis is a "blunt instrument" in Arctic environments. Only recently has this perception been challenged (Gajewski, 2006).

A recent project, Arctic Climate Variability at Several Timescales (ACVAST), has enabled the analysis of many lake sediment cores from across the Canadian Arctic Islands (Fig. 1), providing an array of sites with continuous records of Holocene environmental variability. Multi-proxy analyses (pollen, diatoms and chironomids, biogenic silica and sedimentary properties) are being performed on these cores. Due to the recent publication of several modern datasets for calibration (Barley et al., 2006; Bunbury and Gajewski, subm.; Fortin and Gajewski, subm. a; Gajewski, 1995, 2002; Gajewski et al., 2005; Kerwin, 2000; Ritchie et al., 1987; Whitmore et al., 2005), quantitative reconstructions of past climates from pollen, chironomids and sediment biogenic silica are possible. Modern calibration data from many parts of the Arctic are also available for diatoms (Bouchard et al., 2004) but a lack of sufficient modern analogs, taxonomic difficulties and dissolution of diatoms is hampering down-core reconstruction efforts. Additionally, new high-resolution modern climate data are available for calibration model development (Atkinson and Gajewski, 2002; Atkinson et al., 2000).

\section{Results from the central and western Arctic}

Results from three sites (Fig. 2) show how Holocene climate changes affected terrestrial and aquatic primary production. These sediment cores were dated by radiocarbon and ${ }^{210} \mathrm{~Pb}$ methods. In spite of the well-known difficulties with dating cores in low-organic Arctic sediments (Gajewski et al., 1995), the general reliability of the chronologies is confirmed by stratigraphic correlation with pollen sequences and reconstructions based on glacial geology (for discussion see Peros and Gajewski, 2008a; Peros et al., subm.).

The use of heavy liquid separation as a pollen processing technique (Zabenskie et al., 2006) has increased the feasibility of producing pollen records from Arctic lake sediments to at least centennial resolution. The modern analog method (Overpeck et al., 1985) was used with pollen percentage data of Lakes KR02 and JR01 (Fig. 2) to reconstruct July temperature for the Holocene, and shows that the early Holocene was $1-2^{\circ} \mathrm{C}$ warmer than the early $20^{\text {th }}$ century (Fig. 2; Peros and Gajewski, 2008a; Zabenskie and Gajewski, 2007). However, these estimates, based on percentage pollen data, may underestimate the actual temperature change. This underestimation is suggested by the pollen influx (grains $\mathrm{cm}^{-2} \mathrm{yr}^{-1}$; indicative of pollen and plant production), which shows large changes in production that closely parallel the ice melt record from the Agassiz Ice Cap (Fisher et al., 1995; Fig. 2). Changes in pollen concentrations and influx are important components of pollen records from the Canadian Arctic. Many Arctic plants have broad environmental tolerances, so their ranges are wide and changed little during the Holocene, and pollen percentage diagrams may not indicate high variability. However, plant productivity and density are closely related to climate and are recorded by concentration and influx measures (Gajewski, 1995; Peros and Gajewski, 2008a, b). We also identify a long-term cooling during the mid- to late-Holocene from Melville, Banks, Somerset and Prince of Wales Islands (Gajewski, 1995; Gajewski et al., 2000; Gajewski and Frappier, 2001; Gajewski and Atkinson, 2003; Kauffman et al., 2004; Peros et al, subm.).

Millennial-scale variations, such as those seen in pollen influx at KR02, occur coherently with changes in temperatures interpreted from ice core isotope and melt series (Alley, 2004; Fisher et al., 1995). For example, a period of high pollen influx between 8-7 kyr at KR02 coincides with an increase in temperatures in Greenland and across N. America (Viau et al., 2006),

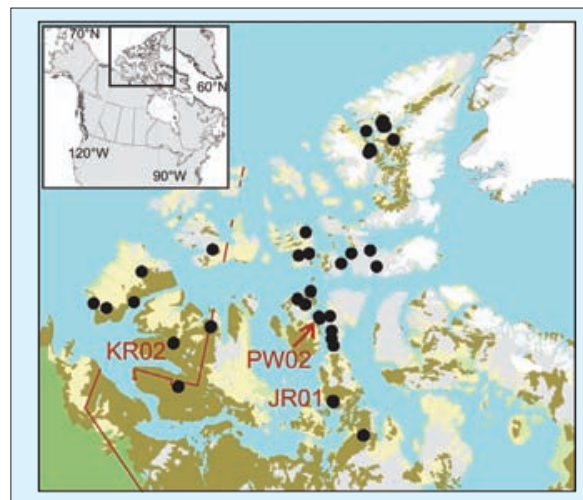

(a) Lake sediment cores

Figure 1: Maps of the Canadian Arctic Archipelago showing research sites of the AVCAST Project a) Locations of lake sediment cores, with the three core sites in Figure 2 highlighted. $\boldsymbol{b})$ Locations of modern lake sediment samples used for compilation of the calibration datasets, classified by the microfossil type. For data see: pollen - Whitmore et al. (2005); chironomid - Gajewski et al. (2005) and Barley et al. (2006); diatom-Bouchard et al. (2004); and ostracode-Bunbury and Gajewski (subm.). and relatively high melt percentages in the Agassiz Ice Cap (Fig. 2).

Diatom-based paleolimnological reconstructions continue to improve as issues around dissolution, taxonomy (e.g., Paull et al., 2008), autecology (ecology of individual species) and biogeography are understood. Cores from different Arctic regions, or even on the same island, have greatly different assemblages (Finkelstein and Gajewski, 2007, 2008), indicating distinct biogeographic patterns and high biodiversity at some sites, in spite of their Arctic locations. While this variability makes it difficult to correlate records across the Arctic, it provides new information on the controls of diatom distribution, and what these organisms represent in fossil sequences. The relationship between diatom diversity and production is complex (Fig. 2), with a negative relationship in some cases (Fig. 2, Lake PW02; Finkelstein and Gajewski, 2008) and a positive one in others (Fig. 2, Lakes JR01 and KR02; LeBlanc et al., 2004; Podritske and Gajewski, 2007); trends likely related to local factors such as habitat complexity and nutrient availability. Sections of many Arctic lake sediment cores lack diatoms but the reasons for these diatom-free zones are not clear (Smith, 2002; Podritskie and Gajewski, 2007; Gajewski, 2008; Paull and Gajewski, subm.).

\section{Regional syntheses}

We have performed multi-proxy syntheses using cores from Victoria Island (KR02) and the Boothia Peninsula (JR01). Only broad-scale trends are coherent between the different proxies in the same core, and differences in the interpretations and reconstructions of these different proxies at the same site remain (Fig. 2; Fortin and Gajewski, subm b; Paull and Gajewski, subm). It is not yet clear if these differences are due to differential climate impacts on the

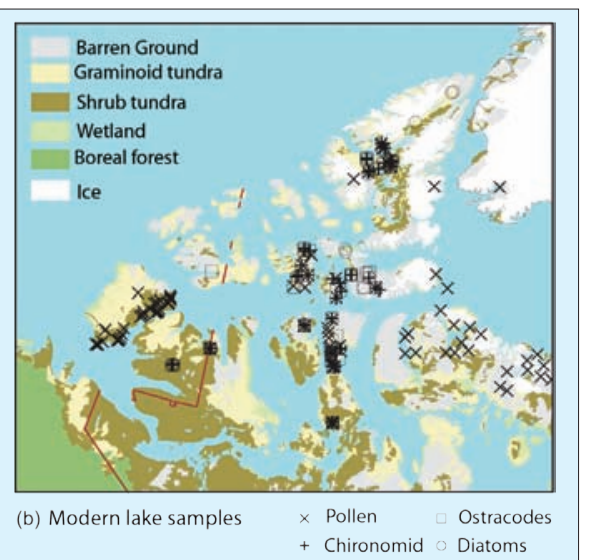


various biological communities, or to deficiencies in the modern calibration datasets used to compute the reconstructions. However, sufficient agreement exists between the ecological interpretations of the proxy data within one core and between the quantitative reconstructions of the proxies to suggest that these issues can be resolved by additional datasets from these regions.

\section{General conclusions}

These new results greatly improve previous estimates of the spatial and temporal extent of early Holocene warmth and subsequent cooling in the Arctic (e.g.,

a) Lake KR02 - Victoria Island

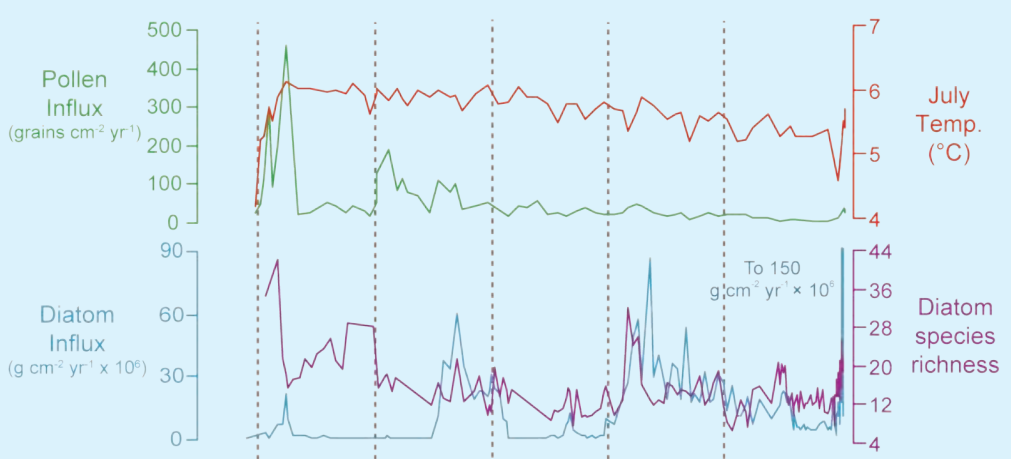

b) Lake PW02 - Russell Island

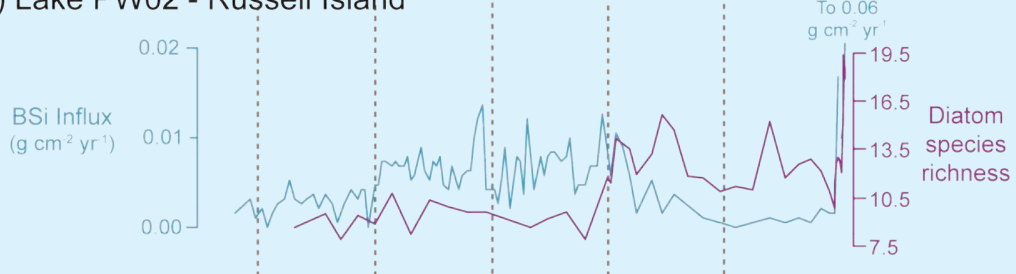

c) Lake JR01 - Boothia Peninsula
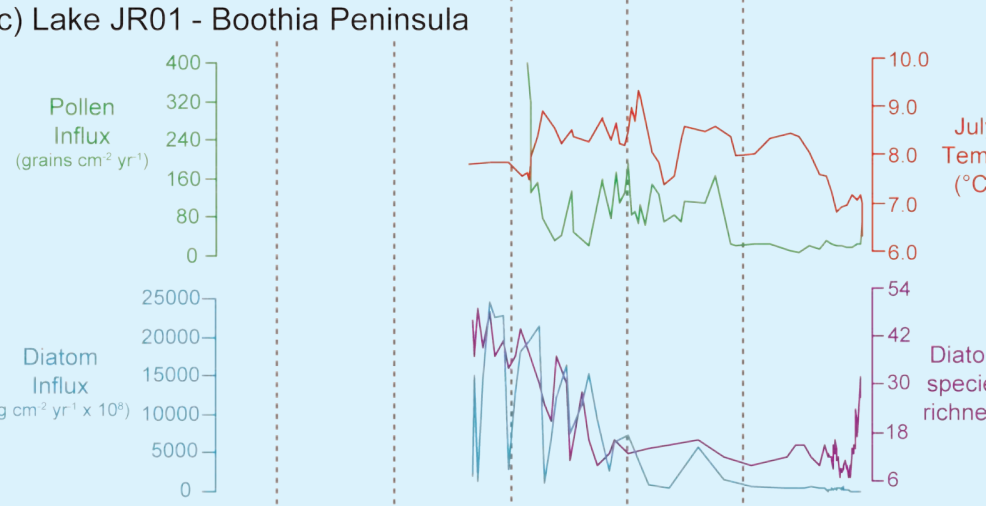

d) Regional paleoclimate records

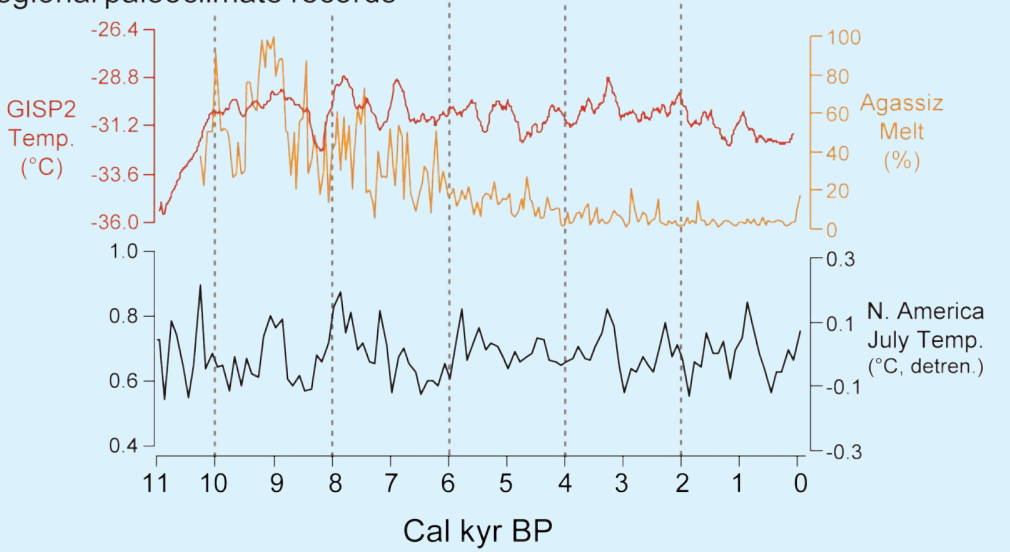

Figure 2: a-c) Paleoenvironmental data from 3 lakes showing pollen influx (green) and pollen-percentage derived temperature reconstruction (red) (KR02, Peros and Gajewski, 2008a; JR01, Zabenskie and Gajewski, 2007), diatom influx (blue) and diatom species richness (purple) (KRO2, Podritske and Gajewski, 2007; PW02, Finkelstein and Gajewski, 2008; JR01, LeBlancet al., 2004). d) N. America pollen-based mean July temperature reconstruction (black, Viau et al., 2006), Agassiz Ice Cap \% melt data (orange, Fisher et al., 1995), and GISP2 ice core paleo-temperature reconstruction (red, Alley, 2004). The very high values of the most recent diatom and sediment biogenic silica (BSi) accumulation records from Lakes KRO2 and PWO2 have been truncated to better show Holocene variability (see publications above).

Gajewski and Atkinson, 2003; Kaufman et al., 2004). Although the number of paleoenvironmental reconstructions in the Canadian Arctic has increased, the site density is still low, and more replication, especially of high temporal-resolution data for the early and mid-Holocene, is needed to quantify the spatial differences in climate and local effects of Holocene climatic changes on ecosystems. In addition, other issues remain, including (a) the need for more modern calibration data and consolidation of existing datasets to improve our ability to reconstruct past climate variables, (b) the need for better taxonomic harmonization across datasets, and (c) difficulties with radiocarbon dating, which in the Canadian Arctic is hampered by a lack of suitable organic material of terrestrial origin and the presence of widespread carbonate bedrock (Gajewski et al., 1995). Despite these challenges, our knowledge of environmental change in the Canadian Arctic has greatly improved and with additional research, a deeper understanding of this important region will no doubt be realized.

All ACVAST data are available on the LPC website (www.lpc.uottawa.ca) and deposited at the NOAA World Data Center for Paleoclimatology (www.ncdc.noaa. gov/paleo/index.html).

\section{Acknowledgements}

ACVAST is funded by the Canadian Foundation for Climate and Atmospheric Sciences.

\section{References}

Finkelstein, S.A. and Gajewski, K., 2008: Responses of Fragilarioid-dominated diatom assemblages in a small Arctic lake to Holocene climatic changes, Russell Island, Nunavut, Canada, Journal of Paleolimnology, DOl:10.1007/s10933-008-9215-5

Gajewski, K. and Atkinson, D., 2003: Climate change in the Canadian Arctic, Environmental Reviews, 11: 69-102.

Peros, M. and Gajewski, K., 2008a: Holocene climate and vegetation change on Victoria Island, western Canadian Arctic, Quaternary Science Reviews, 27: 235-249.

Podritske, B. and Gajewski, K., 2007: Diatom community response to multiple scales of Holocene climate variability in a small lake on Victoria Island, NWT, Canada, Quaternary Science Reviews, 26 : 3179-3196.

Zabenskie, S. and Gajewski, K., 2007: Post-glacial climatic change on Boothia Peninsula, Nunavut, Canada, Quaternary Research, 68 : 261-270.

For full references please consult:

www.pages-igbp.org/products/newsletters/ref2009_1.htm 